\title{
The efficiency of a mixed exercise program on quality of life and fatigue levels in patients with breast cancer
}

\author{
Elif Köse * (D), Menşure Aydin² (D), Osman Köse ${ }^{3}$ (D), \\ Maksut Görkem Aksu (iD, Gülşah Sekban ${ }^{5}$
}

\begin{abstract}
SUMMARY
OBJECTIVE: Exercise is a nonpharmacological supportive therapy which has been specifically identified to reduce postoperative complications or adverse events of cancer or treatments. Although there are few studies combining resistance and aerobic exercise in cancer survivors, exercise programs are very rare in different places in the literature. This study aims to investigate the effects of mixedtype exercise in different venues on weight, body mass index, fatigue, and quality of life in cancer survivors.

METHODS: This is a descriptive, intervention study. Participants were included in the study, and the exercise process was between January and November 2019. The exercise group consisted of 32 patients who had just completed their breast cancer treatment and did not have distant metastases, and they applied a mixed exercise program including resistance at home and aerobic exercise in the fitness center for 12 weeks. The patients with breast cancer in the control group (30 patients) did not receive any exercise program.

RESULTS: Subjective feelings of fatigue and decrease in concentration, motivation, and physical activity significantly decreased after exercise ( $p<0.001, p<0.001, p=0.006, p=0.008$, and $p<0.001$, respectively) in the study group. The results also showed that physical health, general health status, and emotional and social health status significantly increased with the exercise program $(p<0.001, p<0.001$, $p=0.004$, and $p=0.003$, respectively).

CONCLUSION: Our results show that a mixed (fitness center and home) 12-week exercise program provides an improvement in general health and reduces the side effects of the treatments and fatigue in patients with breast cancer. For a good prognostic process after medical treatment, exercise can be recommended in every accessible area.
\end{abstract}

KEYWORDS: Quality of life. Fatigue. Muscle strength. Breast cancer. Exercise.

\section{INTRODUCTION}

According to the 2020 global cancer burden study prepared by the International Agency for Research on Cancer, there were 19.3 million new cancer cases, and approximately 10.0 million deaths worldwide were due to cancer. The incidence of breast cancer in women exceeded the most frequently diagnosed lung cancer, with a prevalence of 2.3 million (11.7\%) newly diagnosed breast cancer appears at the top, followed by lung $(11.4 \%)$, colorectal $(10.0 \%)$, prostate $(7.3 \%)$, and stomach (5.6\%) cancers ${ }^{1}$.

Fatigue experienced by patients with cancer can be caused by cancer or its related treatment processes ${ }^{2}$. This intense fatigue

\footnotetext{
'Sakarya University, Faculty of Medicine, Department of Public Health - Sakarya, Turkey. ${ }^{2}$ Halic University, Department of Physical Education and Sports Education - Istanbul, Turkey. ${ }^{3}$ Sakarya University, Faculty of Medicine, Gynecological Oncology clinic - Sakarya, Turkey. ${ }^{4}$ Kocaeli University, Faculty of Medicine, Department of Radiation Oncology - Kocaeli, Turkey. ${ }^{5}$ Kocaeli University, Department of Physical Education and Sports Education - Kocaeli, Turkey. *Corresponding author: elifkose@sakarya.edu.tr Conflicts of interest: the authors declare there are no conflicts of interest. Funding: none. Received on August 03, 2021. Accepted on August 03, 2021.
} 
causes patients with cancer to have difficulty in performing simple daily life activities and to decrease their ability to participate in regular exercise programs, thus causing deterioration in their general health, social interaction, and health-related quality of life $(\mathrm{QoL})^{3}$.

Fatigue during the cancer treatment process is defined as a clinical problem that is not related to exercise. It does not pass with rest and might even get worse $e^{4}$.

Maintenance of metabolic hemostasis of the organism is possible by keeping ATP levels constant in both skeletal and cardiac muscles by continuous synthesis and degradation through anaerobic and aerobic metabolisms. With exercise, not only skeletal muscle but also all other organs are modulated. It has therapeutic effects on conditions such as autoimmune and neurodegenerative diseases, and cancer with multiple molecular events and adaptations, as well as increasing the power of oxygen use with exercise, increased attenuation corrected perfusion, changes in muscles, and functional capacity and performance ${ }^{5,6}$.

It leads to an increase in the QoL and improvement of health ${ }^{2}$.

However, in recent studies, exercise has been recommended as a part of an applicable, standard care to reduce cancer-related fatigue, improving physical and psychological problems, and increasing $\mathrm{QoL}^{7}$. Exercise is a nonpharmacological supportive therapy which has been specifically described to reduce postoperative complications or adverse effects of treatments and cancer ${ }^{8}$.

Aerobic and resistance exercises immediately after treatment improve muscle strength, body composition, aerobic capacity, and QoL and reduce fatigue'. Recent scientific studies recommend exercise programs that include both resistance and aerobic exercises for patients with breast cancer ${ }^{10}$.

This study aims to investigate the effects of a 12 -week mixed exercise program, including resistance at home and aerobic exercise in the fitness center, on weight, body mass index (BMI), fatigue, and QoL in patients who had previously been treated for breast cancer.

\section{METHODS}

\section{Subjects}

Sixty-two women are included with convenience sampling voluntarily. The power of the study was found to be 0.87 in the post hoc power analysis. Participants were included in the study, and the exercise process was between January and November 2019. The study group (32/62 women) had completed breast cancer treatments (e.g., surgery, chemotherapy, and radiotherapy) without any other organ metastasis and had started routine controls (age, 52.37 \pm 5.38 ; height [m], 1.59 \pm 0.08 ; weight $[\mathrm{kg}]$,

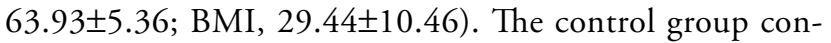
sisted of remaining 30 women who did not participate in the exercise program (age, 52.6 \pm 6.15 ; height, 1.58 \pm 0.07 ; weight,

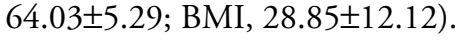

Inclusion criteria for the study were volunteer patients over 18 years of age, literate, not doing regular exercise in the past three years, never developing metastases, and having completed routine treatment.

Exclusion criteria were those who developed metastases and those who exercised regularly were not included in the study.

In the process of inclusion in the study group, care was taken that the breast cancer treatment process was completed and that there was no metastasis. There may be differences in the QoL during different treatment processes in individuals, but the completion of the treatment process was considered the main starting point of the study.

Two exercise programs were applied.

\section{Aerobic exercises}

Aerobic exercises were performed three days a week for $50 \mathrm{~min}$ under the supervision of a sports specialist in a fitness center with permission for the training program. One-on-one interviews were conducted to motivate patients. The aerobic exercise program included $10 \mathrm{~min}$ of warmup, $30 \mathrm{~min}$ of walking and cycling, and $10 \mathrm{~min}$ of cool-down exercises and the program was performed three days/week.

\section{Resistance exercises}

In accordance with the movements in the "exercise for oncology patients" booklet given to each patient by the researcher, the patients were asked to perform exercise at home for $1 \mathrm{~h}$ every day with an exercise mat, Pilates ball, and elastic band. Notably, 10 min of warmup (e.g., neck, trunk, and leg movements); 40 min of elastic band, ball, hip, and stretching movements; and 10 min of cooling activities were performed in the resistance exercises. The directions in the booklet were taught by a sports expert, who is a Pilates instructor, having the participants in the program perform them. While doing resistance exercises, the participants were warned to perform the activities that they can do comfortably among the movements in the booklet and to stop the movement if they feel pain.

The control group consists of individuals whose breast cancer treatments (e.g., surgery, chemotherapy, radiotherapy) have been completed and whose routine controls have begun but who did not perform any exercise. The control group was generally recommended to exercise within the scope of health promotion, but they were not followed up during the research 
process. After the research, facilities and necessary sports materials were provided for the sports center for the control group.

Before starting the study, the required permissions were obtained from the "XXX University Faculty of Medicine Ethics Committee." Information about the study was given to participants, and consent forms were obtained for voluntary participation in the program. An expert oncologist determined the selection of the patients and their suitability for exercise. A WhatsApp group was created for communication, motivation, and follow-up purposes with the study group, and their daily programs were monitored.

\section{Data collection materials}

EORTC-QLQ-C30 includes 30 questions and three subtitles: general well-being, functional difficulties, and symptom control. The higher the score, the better the QoL in the general health status and function scales. In the symptom scales, the higher the score, the worse the QoL. Functional scales includes physical, role, cognitive, emotional, and social functions. On the symptom scales, weakness, pain, and nausea/vomiting are evaluated. In addition, dyspnea, insomnia, loss of appetite, constipation, diarrhea, and financial difficulties are measured with one question each ${ }^{11}$. Content validity and reliability study of the scale was conducted in our country, Cronbach's alpha coefficient was $\alpha=0.9014^{12}$.

CIS (Checklist Individual Strength or CIS) Questionnaire was used to measure the general fatigue level of individuals. It was developed by Vercoulen et al. and adapted to Turkish by Ergin and is the most widely used survey worldwide to evaluate chronic fatigue ${ }^{13,14}$.

As a result of the reliability analyses of the CIS-T questionnaire, the Cronbach's alpha coefficient was $\alpha=0.87$. According to this scale, fatigue is evaluated from four aspects: subjection perception of fatigue, decrease in concentration, decrease in motivation, and decrease in physical activity. The questionnaire consists of 20 statements that measure the exhaustion of the last two weeks, and a seven-point scale is used for the answers.

\section{Data collection method}

It was obtained through face-to-face interviews with people who met the appropriate criteria, who wanted to be included in the study, for about a year. Participation in the exercise group was voluntary. Data were collected in the same way for the second time with the same people 12 weeks after the first interview.

\section{Statistical analysis}

Data analysis was performed using SPSS 21.0 software (IBM Corporation, Armonk, NY, USA). Whether the distributions of CIS and EORTC QLQ-30 scores were normal or not normal were determined visually (by histograms and probability plots) and by analytical methods (Shapiro-Wilk tests). Descriptive analyses were presented using medians and first and third percentiles for the non-normally distributed variables. Categorical variables are specified as numbers and percentages. Mann-Whitney $U$ test was used to analyze the data. Dependent variables were presented using the Wilcoxon test. The significance level for all of the statistical tests was set at $\mathrm{p}<0.05$.

\section{RESULTS}

In this study, after 12 weeks of aerobic exercise and home-based resistance exercises, the weight, which was $63.93 \pm 5.36$, became $62.37 \pm 5.60$, and the BMI, which was $29.44 \pm 10.46$, reduced to $28.67 \pm 10.29$. In the control group, the weight within the same period changed over time from $64.03 \pm 5.29-66.23 \pm 6.26$; BMI changed from $28.85 \pm 12.12-29.26 \pm 9.41$.

The subjective perception of fatigue and decline in concentration, motivation, and physical activity decreased statistically significantly after exercise $(\mathrm{p}<0.001, \mathrm{p}=0.001$, $\mathrm{p}<0.001$, and $\mathrm{p}<0.001$, respectively, Table 1$)$. The decrease in the scores of the scale subdimensions in the study group showed a more significant decrease than the control group. When the difference between the pre-post exercise scores in the study group and pre-post scores of the control group were compared, it was found that, except for the decrease in concentration, the difference in the subjective perception of fatigue and decline in concentration, motivation, and physical activity was statistically and significantly higher in the study group $(\mathrm{p}<0.001, \mathrm{p}=0.227, \mathrm{p}=0.042, \mathrm{p}=0.035$, and $\mathrm{p}=0.002$, respectively, Table 1$)$.

When the postexercise values of the study group and the control group were compared, it was found that the scores of the study group for the subjective fatigue and decrease in concentration, motivation, and physical activity were statistically significantly lower than the control group scores $(\mathrm{p}<0.001$, $\mathrm{p}<0.001, \mathrm{p}=0.006$, and $\mathrm{p}=0.008$, respectively, Table 2 ).

An improvement in general health status with exercise; a statistically significant increase in the physical, role, emotional, and social dimensions in the functional health status subdimension $(\mathrm{p}<0.001, \mathrm{p}=0.013, \mathrm{p}<0.001$, and $\mathrm{p}<0.001$, respectively); and a statistically significant decrease in fatigue, pain, insomnia, and financial support ( $<<0.001, \mathrm{p}<9.991, \mathrm{p}=0.014$, and $\mathrm{p}=0.004$, respectively, Table 3 ) were found.

In Table 3, comparing the study group and the control group, it was found that general health status and physical, role, emotional, and social functions were higher and statistically 
Table 1. Relationship of exercise and fatigue level in the intervention and control groups.

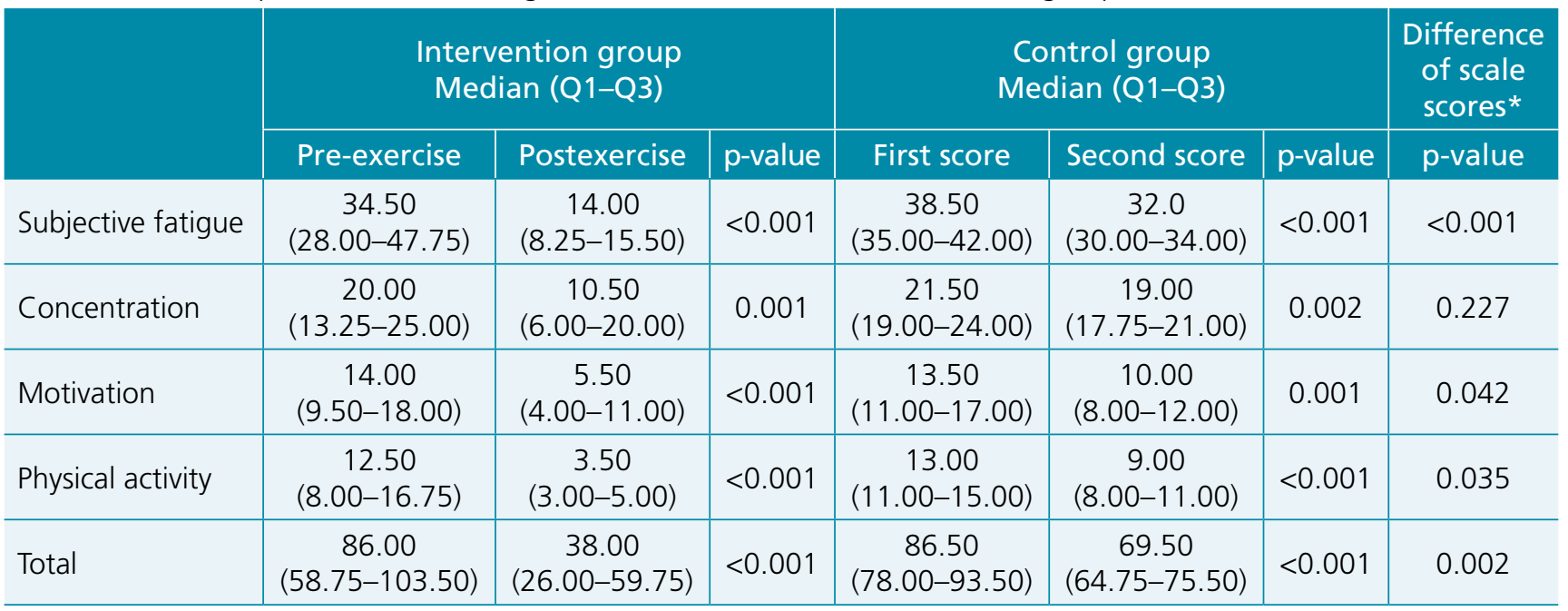

*Comparison of first and second measurement differences between control and study groups.

Table 2. Comparison of group measurements and control group CIS scores after exercise.

\begin{tabular}{l|c|c|l} 
& The exercise group Median (Q1-Q3) & The control group Median (Q1-Q3) & $\mathrm{p}$-value \\
\hline Subjective fatigue & $14.00(8.25-15.50)$ & $32.0(30.00-34.00)$ & $<0.001$ * \\
\hline Concentration & $10.50(6.00-20.00)$ & $19.00(17.75-21.00)$ & $<0.001 *$ \\
\hline Motivation & $5.50(4.00-11.00)$ & $10.00(8.00-12.00)$ & $0.006^{*}$ \\
\hline Physical activity & $3.50(3.00-5.00)$ & $9.00(8.00-11.00)$ & $0.008^{*}$ \\
\hline Total & $38.00(26.00-59.75)$ & $69.50(64.75-75.50)$ & $<0.001 *$ \\
\hline
\end{tabular}

*Mann-Whitney U test; CIS: checklist individual strength.

significant $(\mathrm{p}<0.001, \mathrm{p}<0.001, \mathrm{p}=0.028, \mathrm{p}=0.004$, and $\mathrm{p}=0.003$, respectively, Table 3$)$.

\section{DISCUSSION}

In this study, in which the effects of aerobic and home-based resistance exercises on BMI, fatigue, and QoL were examined in patients with breast cancer whose treatment was completed, it was found that training had positive effects. While BMI decreased in the exercising group in the study, Wilson et al. ${ }^{15}$ showed that exercise reduced the BMI, body weight, and fat ratio of women with breast cancer. Statistically significant decreases were observed in BMI over time in studies in which exercise program was applied for 12 and 21 weeks $^{3,15}$.

A controlled, medium- to high-intensity, combined resistance, and aerobic exercise program is the most effective program for patients with breast cancer undergoing adjuvant chemotherapy. In a study investigating the impact of a personalized exercise intervention on body composition in patients with breast cancer undergoing treatment, significant differences were observed between exercising and not exercising groups ${ }^{3}$. In a study conducted on 54 people diagnosed with breast cancer, the EORTC scale applied three times a week after nine months of exercise showed a statistically significant positive change in all variables of general and functional health status. There was also an improvement in pain and fatigue in the exercise group compared with the control group ${ }^{16}$.

In a study where home-based and aerobic exercise groups were compared with the nonexercising group, muscle strength and fatigue achieved better results in the exercising group. Kessels et al. ${ }^{17}$ showed that aerobic exercises are more effective than combined aerobic and resistance exercises in cancer-related fatigue. In a study where training was applied to women who had received breast cancer treatment, it was found that fatigue and depressive symptoms decreased ${ }^{18}$.

A 6-week home-based mixed aerobic and resistance exercise program increased physical activity level in colorectal cancer survivors $^{19}$. In the study, which included 40 people 
Table 3. Relationship between exercise and quality of life in the intervention group.

\begin{tabular}{|c|c|c|c|c|c|}
\hline \multirow{2}{*}{$\begin{array}{l}\text { European Organization } \\
\text { for the Research } \\
\text { and Treatment of } \\
\text { Cancer, Quality of Life } \\
\text { Questionnaire -30 }\end{array}$} & Before exercise & After exercise & \multirow[t]{2}{*}{ p-value* } & $\begin{array}{l}\text { Control group } 2 \\
\text { score }\end{array}$ & $\begin{array}{c}\text { Difference } \\
\text { of scale } \\
\text { scores }^{\mathrm{a}} \\
\end{array}$ \\
\hline & $\begin{array}{l}\text { Median } \\
\text { (Q1-Q3) }\end{array}$ & $\begin{array}{l}\text { Median } \\
\text { (Q1-Q3) }\end{array}$ & & $\begin{array}{l}\text { Median } \\
\text { (Q1-Q3) }\end{array}$ & p-value** \\
\hline Global health status & $\begin{array}{c}50.00 \\
(25.00-58.33)\end{array}$ & $\begin{array}{c}83.33 \\
(83.33-91.67)\end{array}$ & $<0.001$ & $\begin{array}{c}54.17 \\
(50.00-66.67)\end{array}$ & $<0.001$ \\
\hline \multicolumn{6}{|l|}{ Fonksiyonel } \\
\hline Physical & $\begin{array}{c}60.00 \\
(46.67-80.00)\end{array}$ & $\begin{array}{c}86.67 \\
(80.00-93.33)\end{array}$ & $<0.001$ & $\begin{array}{c}73.33 \\
(66.67-80.00)\end{array}$ & $<0.001$ \\
\hline Role & $\begin{array}{c}75.00 \\
(37.50-100.00)\end{array}$ & $\begin{array}{c}83.33 \\
(66.67-100.00)\end{array}$ & 0.013 & $\begin{array}{c}66.67 \\
(66.67-83.33)\end{array}$ & 0.028 \\
\hline Cognitive & $\begin{array}{c}83.33 \\
(66.67-100.00) \\
\end{array}$ & $\begin{array}{c}83.33 \\
(66.67-100.00) \\
\end{array}$ & 0.740 & $\begin{array}{c}75.00 \\
(66.67-87.50) \\
\end{array}$ & 0.412 \\
\hline Emotional & $\begin{array}{c}75.00 \\
(41.67-89.58) \\
\end{array}$ & $\begin{array}{c}100.00 \\
(54.17-100.00) \\
\end{array}$ & $<0.001$ & $\begin{array}{c}75.00 \\
(62.50-83.33) \\
\end{array}$ & 0.004 \\
\hline Social & $\begin{array}{c}66.67 \\
(33.33-83.33) \\
\end{array}$ & $\begin{array}{c}100.00 \\
(83.33-100.00) \\
\end{array}$ & $<0.001$ & $\begin{array}{c}83.33 \\
(66.67-100.00) \\
\end{array}$ & 0.003 \\
\hline \multicolumn{6}{|l|}{ Symptoms } \\
\hline Fatigue & $\begin{array}{c}55.56 \\
36.11-77.78 \\
\end{array}$ & $\begin{array}{c}33.33 \\
22.22-55.56 \\
\end{array}$ & $<0.001$ & $\begin{array}{c}33.33 \\
33.33-47.22 \\
\end{array}$ & 0.177 \\
\hline Nausea & $\begin{array}{c}16.67 \\
0-29.17 \\
\end{array}$ & $\begin{array}{c}0 \\
0-16.67 \\
\end{array}$ & 0.100 & $\begin{array}{c}16.67 \\
0-33.33 \\
\end{array}$ & 0.018 \\
\hline Pain & $\begin{array}{c}50.00 \\
16.67-83.33\end{array}$ & $\begin{array}{c}33.33 \\
16.67-50.00 \\
\end{array}$ & $<0.001$ & $\begin{array}{c}33.33 \\
16.67-50.00\end{array}$ & 0.453 \\
\hline Dyspnea & $\begin{array}{c}0 \\
0-33.33 \\
\end{array}$ & $\begin{array}{c}0 \\
0-33.33 \\
\end{array}$ & 0.485 & $\begin{array}{c}33.33 \\
0-33.33\end{array}$ & 0.299 \\
\hline Insomnia & $\begin{array}{c}33.33 \\
8.33-66.67\end{array}$ & $\begin{array}{c}33.33 \\
0-66.67\end{array}$ & 0.014 & $\begin{array}{c}33.33 \\
0-41.67\end{array}$ & 0.642 \\
\hline Appetite loss & $\begin{array}{c}0 \\
0-33.33\end{array}$ & $\begin{array}{c}0 \\
0-33.33\end{array}$ & 0.281 & $\begin{array}{c}33.33 \\
0-33.33\end{array}$ & 0.033 \\
\hline Constipation & $\begin{array}{c}0 \\
0-33.33 \\
\end{array}$ & $\begin{array}{c}0 \\
0-25.00 \\
\end{array}$ & 0.135 & $\begin{array}{c}16.67 \\
0-33.33 \\
\end{array}$ & 0.038 \\
\hline Diarrhea & $\begin{array}{c}0 \\
0-33.33\end{array}$ & $\begin{array}{l}0 \\
0\end{array}$ & 0.166 & $\begin{array}{c}0 \\
0-33.33 \\
\end{array}$ & 0.055 \\
\hline Financial impact & $\begin{array}{c}33.33 \\
0-66.67 \\
\end{array}$ & $\begin{array}{c}0 \\
0-33.33 \\
\end{array}$ & 0.004 & $\begin{array}{c}33.33 \\
0-33.33 \\
\end{array}$ & 0.123 \\
\hline
\end{tabular}

*Wilcoxon test; Q: quartile; **Mann-Whitney $U$ test. ${ }^{2}$ Comparison of measurements of the study group after exercise and European Organization for the Research and Treatment of Cancer, Quality of Life Questionnaire scale scores of the control group.

who exercised at home and in the fitness room for 10 weeks after cancer treatment, there was an improvement in physical function and body composition ${ }^{20}$. It is stated in the literature that cancer survivors mostly prefer physical exercise programs at home. The flexibility of the schedule at home in terms of time planning is beneficial for exercise and for individuals to organize their own work ${ }^{21}$. The fact that there were exercises in the fitness room in addition to home exercise in the study eliminated the possible limitations of only home exercises. While going to the fitness center provided motivation with one-to-one interaction, it contributed to supervised exercise and allowed social interaction ${ }^{22}$. 


\section{CONCLUSIONS}

It has been determined that for the women who have completed breast cancer treatment, the 12-week planned exercise program causes a decrease in BMI, an improvement in QoL, a reduction in decreased motivation, lack of concentration and fatigue, an increase in QoL, and a decrease in symptoms of insomnia and pain that may occur with the treatment.

Overall, these results hold promise for the benefit of mixed exercise to improve QoL and physical functioning in breast cancer survivors.

In interventions for cancer survivors, it is recommended to develop a standard exercise program to be applied at home and in different places, in terms of causing easy adaptation and increasing the QoL of the patients.

\section{AUTHORS" CONTRIBUTION}

EK: Conceptualization, Data curation, Formal analysis, Writing - original draft. MA: Conceptualization, Data Curation, Project administration, Supervision, Writing review \& editing, Writing - original draft. OK: Resources, Formal analysis. GS: Resources, Formal analysis. MGA: Project administration, Supervision, Writing - review \& editing.

\section{REFERENCES}

1. Sung H, Ferlay J, Siegel RL, Laversanne M, Soerjomataram I, Jemal A, Bray F. Global Cancer Statistics 2020: GLOBOCAN estimates of incidence and mortality worldwide for 36 cancers in 185 countries. CA Cancer J Clin. 2021;71(3):209-49. https:// doi.org/10.3322/caac.21660

2. World Health Organization. 2010, Global Recommendations on Physical Activity for Health. Geneva: World Health Organization; 2010. [cited on May 2, 2021]. Available from: https://www. who.int/dietphysicalactivity/global-PA-recs-2010.pdf

3. Battaglini C, Bottaro M, Dennehy C, Rae L, Shields E, Kirk D, et al. The effects of an individualized exercise intervention on body composition in breast cancer patients undergoing treatment. Sao Paulo Med J. 2007;125(1):22-8. https://doi. org/10.1590/s1516-31802007000100005

4. Schmidt ME, Wiskemann J, Armbrust P, Schneeweiss A, Ulrich $\mathrm{CM}$, Steindorf K. Effects of resistance exercise on fatigue and quality of life in breast cancer patients undergoing adjuvant chemotherapy: a randomized controlled trial. Int J Cancer. 2015;137(2):471-80. https://doi.org/10.1002/ijc.29383

5. Suarez RK. Energy and metabolism. Compr Physiol. 2012;2(4):2527-40. https://doi.org/10.1002/cphy.c110009

6. Philippou A, Chryssanthopoulos C, Maridaki M, Dimitriadis $G$, Koutsilieris M. Exercise metabolism in health and disease. In: Kokkinos $\mathrm{P}$, Narayan $\mathrm{P}$, editors. Cardiorespiratory fitness in cardiometabolic diseases. Springer, Cham; 2019: 57-96. https://doi.org/10.1007/978-3-030-04816-7_5

7. Makluf ASD, Barra AA, Figueiredo EM, Silva GR, Ribeiro RFR, Barros $C P$, et al. Influence of physical activity on the quality of life of breast cancer patients. Biomed J Sci \& Tech Res. 2018;10(3):7787-90. https://doi.org/10.26717/ BJSTR.2018.10.001948

8. Johnsson A, Demmelmaier I, Sjövall K, et al. A single exercise session improves sideeffects of chemotherapy in women with breast cancer: an observational study. BMC Cancer. 2019;19(1):1073. https://doi.org/10.1186/s12885-019-6310-0

9. Cešeiko R, Eglītis J, Srebnijs A, Timofejevs M, Purmalis E, Erts $R$, et al. The impact of maximal strength training on quality of life among women with breast cancer undergoing treatment. Exp Oncol. 2019;41(2):166-72. https://doi.org/10.32471/ exp-oncology.2312-8852.vol-41-no-2.13249
10. Volaklis KA, Halle M, Tokmakidis SP. Exercise in the prevention and rehabilitation of breast cancer. Wien Klin Wochenschr. 2013;125(11-12):297-301. https://doi.org/10.1007/s00508013-0365-8

11. Aaronson NK, Ahmedzai S, Bergman B, Bullinger M, Cull A, Duez NJ, et al. The European Organization for Research and Treatment of Cancer QLQ-C30: a quality-of-life instrument for use in international clinical trials in oncology. J Natl Cancer Inst. 1993;85(5):365-76. https://doi.org/10.1093/jnci/85.5.365

12. Beşer NG, Öz F. Anxiety-depression levels and quality of life of patients with lymphoma receiving chemotherapy. Journal of Cumhuriyet University School of Nursing. 2003 [cited on May 3, 2021];7(1):47-58. Available from: http://eskidergi. cumhuriyet.edu.tr/makale/623.pdf

13. Vercoulen JH, Swanink CM, Fennis JF, Galama JM, van der Meer JW, Bleijenberg G. Dimensional assessment of chronic fatigue syndrome. J Psychosom Res. 1994;38(5):383-92. https://doi.org/10.1016/0022-3999(94)90099-x

14. Ergin $G$, Yildirim $Y$. A validity and reliability study of the Turkish Checklist Individual Strength (CIS) questionnaire in musculoskeletal physical therapy patients. Physiother Theory Pract. 2012;28(8):62432. https://doi.org/10.3109/09593985.2011.654321

15. Wilson DB, Porter JS, Parker G, Kilpatrick J. Anthropometric changes using a walking intervention in African American breast cancer survivors: a pilot study. Prev Chronic Dis. 2005;2(2):A16. PMID: 15888227

16. Santos WDND, Vieira A, Lira CAB, Mota JF, Gentil P, Freitas Junior $R$, et al. Once a week resistance training improves muscular strength in breast cancer survivors: a randomized controlled trial. Integr Cancer Ther. 2019;18:1534735419879748. https:// doi.org/10.1177/1534735419879748

17. Kessels E, Husson O, van der Feltz-Cornelis CM. The effect of exercise on cancer-related fatigue in cancer survivors: a systematic review and meta-analysis. Neuropsychiatr Dis Treat. 2018;14:479-94. https://doi.org/10.2147/NDT.S150464

18. Rogers LQ, Courneya KS, Anton PM, Verhulst S, Vicari SK, Robbs RS, et al. Effects of a multicomponent physical activity behavior change intervention on fatigue, anxiety, and depressive symptomatology in breast cancer survivors: randomized trial. Psychooncology. 2017;26(11):1901-6. https://doi.org/10.1002/pon.4254 
19. Lee MK, Kim NK, Jeon JY. Effect of the 6-week home-based exercise program on physical activity level and physical fitness in colorectal cancer survivors: a randomized controlled pilot study. PLoS One. 2018;13(4):e0196220. https://doi.org/10.1371/ journal.pone.0196220

20. Gorzelitz JS, Stoller S, Costanzo E, Gangnon R, Koltyn K, Dietz AT, et al. Improvements in strength and agility measures of functional fitness following a telehealth-delivered home-based exercise intervention in endometrial cancer survivors. Support Care Cancer. 2021. https://doi.org/10.1007/s00520-021-06415-2
21. Wong JN, McAuley E, Trinh L. Physical activity programming and counseling preferences among cancer survivors: a systematic review. Int J Behav Nutr Phys Act. 2018;15(1):48. https://doi. org/10.1186/s12966-018-0680-6

22. Batalik L, Winnige $P$, Dosbaba F, Vlazna D, Janikova $A$. Home-Based aerobic and resistance exercise interventions in cancer patients and survivors: a systematic review. Cancers (Basel). 2021;13(8):1915. https://doi.org/10.3390/ cancers 13081915 